・研究报告・

\title{
滇西太保山森林公园子囊菌门虫生 真菌物种多样性及其消长动态
}

陈自宏 ${ }^{1}$ 王元兵 ${ }^{2}$ 代永东 ${ }^{2}$ 陈 凯 ${ }^{1}$ 徐玲 ${ }^{*}$ 何謦成 $3^{*}$

1 (保山学院高黎贡山生物资源研究所, 云南保山 678000)

2 (云南大学中草药生物资源研究所云百草实验室, 昆明 650091)

3 (云南农业大学学报编辑部, 昆明 650201)

\begin{abstract}
摘要: 云南及青藏高原存在着丰富的虫生真菌资源。本文选择云南省保山市省级城市森林公园太保山森林公园为 研究区域, 对子囊菌门虫生真菌物种多样性及其季节消长动态开展了系统研究。在2016年每月采集土样和罹病昆 虫, 分离虫生真菌菌株, 采用多基因 $(n r S S U, n r L S U, E F-1 \alpha, R P B 1$ 和 $R P B 2)$ 系统发育分析进行物种鉴定, 通过 $\alpha$ 多样 性分析来研究虫生真菌的数量特征和种群消长动态。太保山森林公园子囊菌门虫生真菌全年均有分布, 共获得395 个菌株, 包括3科9属24种; 优势属为虫草属(Cordyceps) (6个种199个菌株), 白僵菌属(Beauveria) (5个种 80 个菌株), 优势种依次为Akanthomyces sp. Cordyceps tenuipes、C. cicadae、C. fumosorosea和Beauveria bassiana。7月菌株检 出率最高(85株, 占总数的 $21.4 \%$ ), 8 月物种丰富度(15种)和多样性指数(2.35)最高。在 5 个优势种中, 只有Cordyceps cicadae受季节变化影响较大, 集中分布于5-9月, 7月分布最丰富(35株, 占该月菌株总数的 $41.2 \%$ ); 其他 4 个种一年 大部分时间(11或12个月)都能检测到。结果表明, 太保山森林公园子囊菌门虫生真菌资源丰富, 多数优势种对季节 变化适应能力较强。
\end{abstract}

关键词：太保山森林公园; 虫生真菌; 物种多样性; 优势属种; 消长动态

\section{Species diversity and seasonal fluctuation of entomogenous fungi of Ascomycota in Taibaoshan Forest Park in western Yunnan}

\author{
Zihong Chen ${ }^{1}$, Yuanbing Wang ${ }^{2}$, Yongdong Dai ${ }^{2}$, Kai Chen ${ }^{1}$, Ling $\mathrm{Xu}^{1^{*}}$, Qingcheng $\mathrm{He}^{3^{*}}$ \\ 1 Institute of Biological Resources of Gaoligong Mountains, Baoshan University, Baoshan, Yunnan 678000 \\ 2 Yunnan Herbal Laboratory, Institute of Herbal Biotic Resources, Yunnan University, Kunming 650091 \\ 3 Editorial Office of Journal of Yunnan Agricultural University, Kunming 650201
}

\begin{abstract}
Yunnan Province and the Tibetan Plateau are home to a large diversity of entomogenous fungi. We selected Taibaoshan Forest Park of Baoshan City, in Yunnan to investigate the species diversity of entomogenous fungi of Ascomycota and their seasonal fluctuations throughout the year. We collected samples of soil and infected insects monthly in 2016, and the entomogenous fungal strains were isolated before multigene ( $n r S S U, n r L S U, E F-1 \alpha, R P B 1$, and $R P B 2$ ) phylogenetic analyses were used to identify species. Finally we quanitifed the fluctuations throughout the year in alpha diversity. Entomogenous fungi of Ascomycota in Taibaoshan Forest Park were found through the entire year and we identified a total of 395 fungal strains, including 24 species from nine genera of three families. Cordyceps (199 strains of six species) and Beauveria (80 strains of five species) were the dominant genera. Akanthomyces sp., Cordyceps tenuipes, C. cicadae, C. fumosorosea and Beauveria bassiana were the dominant species. The detection rate of strains was the highest (85 strains, $21.4 \%$ of the total) in July, But the species richness (15 species) and Shannon-Wiener diversity index (2.35) were the highest in August. Among the five most dominant species,
\end{abstract}

收稿日期: 2019-04-18; 接受日期: 2019-06-21

基金项目: 国家自然科学基金地区基金(31460153)、云南省科技厅地方本科高校基础研究联合专项资金重点项目(2017FH001-126)、云南省科技厅地方 本科高校基础研究联合专项资金面上项目(2017FH001-029)、保山市第六批中青年学术和技术带头人项目(bszqnxshjsdtr201701)、中国博士后科学基金 面上项目(2017M613017)和云南省高校滇西昆虫资源保护与利用重点实验室建设项目。

* 共同通讯作者 Co-authors for correspondence. E-mail: xuling09083@163.com; 358779197@qq.com 
only C. cicadae was much affected by seasonal changes: occurring from May to September and being most prosperous in July (35 strains, $41.2 \%$ of the total strains in July). The other four species were detected through most of the year (11 or 12 months), indicating a constant abundance of entomogenous Ascomycota were abundant in Taibaoshan Forest Park, regardless of seasonal changes.

Key words: Taibaoshan Forest Park; entomogenous fungi; species diversity; dominant genera and species; population dynamics

自然界中的虫生真菌种类繁多、资源极为丰 富。很多虫生真菌在生防或医药上具有良好的应用 前景, 如球孢白僵菌(Beauveria bassiana)、金龟子绿 僵菌(Metarhizium anisopliae)等种类是自然界中平 衡和调节害虫种群消长的重要生物因子, 在森林和 农田害虫生态控制中具有重要的作用(李增智, 2015); 蛹虫草等种类含有虫草酸、多糖、腺苷等活 性成分, 具有明显的药理作用, 是珍贵的中药材(姜 雪等, 2017)。

早期物种分类主要依据形态特征, 而多基因系 统进化分析的应用, 使虫生真菌的物种分类鉴定取 得了长足进展(王萌等, 2014)。通过多基因系统进化 分析及物种修订, 目前将虫生真菌物种主要归属于 子囊菌门粪壳菌纲肉座菌目的虫草科、线虫草科和 麦角菌科(Sung et al, 2007), 接合菌门虫霉亚门中的 一大类群, 壶菌门壶菌纲中侵染蚊子的一类真菌, 担子菌门层菌纲中的隔担耳菌等(Sinha et al, 2016)。 依据Kepler等(2017)的观点: 虫草科包括虫草属 (Cordyceps)、多孔囊菌属(Ascopolyporus)、布莱克 威尔需属(Blackwellomyces)、白僵菌属(Beauveria)、 侧齿霉属(Engyodontium)、刺束梗孢属 (Akanthomyces)、球束梗狍属(Gibellula)、单梗霉属(Simplicillium)、哈氏霉属(Hevansia)、厚盖霉属(Hyperdermium) 和拟侧齿霉属(Parengyodontium), 共11个属; 棒束孢属的一些物种被归到虫草属, 一些以粉棒束 狍(Isaria farinosa)为名上传的材料被归到刺束梗狍 属(Akanthomyces)。依据Quandt等(2014)的观点, 线 虫草科包括线虫草属(Ophiocordyceps)、弯颈霉属 (Tolypocladium)、掘氏梅里属(Drechmeria)、钩丝狍 属(Harposporium)、紫狍需属(Purpureocillium)、多 头霉属(Polycephalomyces)共6个属。依据Kepler等 (2014)和Luangsa-ard等(2017)的观点, 麦角菌科的 虫生真菌包括绿僵菌属(Metarhizium)、普可尼亚菌 属(Pochonia)、泛普可尼亚菌属(Metapochonia)、奈 杰尔菌属(Nigelia), 以及侵染蚧壳虫的亚肉座菌属
(Hypocrella)、莫勒菌属(Moelleriella)、赛缪尔斯菌 属(Samuelsia)、堆壳菌属(Regiocrella)和座壳狍属 (Aschersonia) 等; 其中绿僵菌属为最大的属, 目前 至少包括50种(Kepler et al, 2014; 陈自宏等, 2018)。

虫生真菌的物种和数量因地理位置、气候和植 被等因素不同而差异很大(李文英等, 2003)。森林生 态系统中生态环境的多样化有利于虫生真菌形成 物种多样性(Yosiaki Itô, 1997), 加强对森林生态系 统中虫生真菌的物种多样性和分布规律研究, 对了 解其自然分布状况及其种质资源的保护和合理利 用具有重要意义。

太保山位于云南省保山市隆阳区城西, 地处横 断山系腹部、怒山山脉南段、高黎贡山山脉东麓, 是 保山著名的城市森林公园, 具有秀丽的自然山水景 观和人文景观。太保山森林公园海拔落差较小 (1,700-1,900 m), 植被类型为中山半湿性常绿阔叶 林, 总面积485.7 ha, 被开发的区域面积较小, 原生 态区域面积较大, 动植物资源丰富, 森林覆盖率达 $90.5 \%{ }^{1}$ 。此区域属中山亚热带温湿季风气候, 常年 温湿度适宜 (平均温度 $10-28{ }^{\circ} \mathrm{C}$, 平均湿度 40\%-83\%), 尤其是夏季气候温暖、雨量充沛, 为虫 生真菌的生长提供了良好条件。关于太保山森林公 园生物资源的研究很少, 对其虫生真菌资源的研究 尚属空白。本研究在太保山森林公园进行了为期 1 年的子囊菌门虫生真菌资源调查, 通过多基因发育 分析进行物种鉴定，通过 $\alpha$ 多样性分析来探讨一年 中不同月份虫生真菌的动态分布规律。

\section{材料与方法}

\section{1 样品采集和虫生真菌菌株分离}

太保山森林公园优势树种包括麻栋(Quercus acutissima)、云南松(Pinus yunnanensis)、蒙自桦 (Betula alnoides)和西南木荷(Schima wallichii)等。根

(1) 王薛昆 (2009) 从保山永昌古城现状看其保护的得失. 硕士学位论 文, 昆明理工大学, 昆明. 
据太保山森林公园的生态环境特点, 分别在 4 种优 势树种林区设置样方, 每个样方总面积为 $400 \mathrm{~m}^{2}$ $(20 \mathrm{~m} \times 20 \mathrm{~m})$, 取 4 个 $2 \mathrm{~m} \times 2 \mathrm{~m}$ 的对角小样方和 1 个 $2 \mathrm{~m} \times 2 \mathrm{~m}$ 的中心小样方。每月在样方中采集罹病昆 虫和土壤样品, 装入保鲜袋, 用记号笔标号。样品 采集后在 $4{ }^{\circ} \mathrm{C}$ 下暂时保存, 并于 3 天内处理。

土壤样品采用黄粉虫诱导分离菌株, 参考 Keyser等(2015)的方法进行; 罹病昆虫采用组织分 离或孢子分离。纯化的菌株用试管斜面培养后于冰 箱 $4^{\circ} \mathrm{C}$ 保存。

\section{2 菌株的物种鉴定}

在PDA培养基上培养虫生真菌菌株, 通过形态 学特征进行初步鉴定, 再结合5 基因序列( $n r S S U$, $n r L S U, E F-1 \alpha, R P B 1$ 和 RPB2)的系统发育分析来确 定虫生真菌的分类地位(Sung et al, 2007; Chen et al, 2013)。

根据近年来对虫生真菌的研究报道(Sung et al, 2007; 代永东等, 2016; Kepler et al, 2017), 检索并 下载了GenBank数据库中已登录的虫生真菌 5 个基 因序列(附录1)。对 个基因数据矩阵序列进行比对, 用“ $\mathrm{N}$ ”表示片段的缺失, 对得到的 5 个基因数据矩阵 序列进行拼接合并, 以 Hydropisphaera peziza 和 Clonostachys rosea作为外类群, 用RAxML软件进 行多基因系统发育分析，确定各菌株的分类地位。

在每个虫生真菌物种中选取1-2个代表性菌株 (共选取了 30 株菌)显示在系统发育树上, 将其5个基 因序列上传到GenBank并获得序列号。

\section{3 虫生真菌的消长动态}

于2016年每月在太保山森林公园进行2-3次调 查(每10-15天一次), 统计分析不同月份中不同物种 的菌株数量变化。记录各月份采集地的空气温度和 湿度。物种的重要值(IV)计算以物种的相对密度值 表示 $(\mathrm{IV}=$ 虫生真菌物种个体数/全部物种个体数 之和)。采用 $\alpha$ 多样性分析研究样地中虫生真菌数量 特征, 不同月份的物种多样性指数、丰富度指数、 均匀度指数和优势度指数用R2.12.1软件进行统计 分析(薛毅和陈立萍, 2006)。

\section{结果}

\section{1 子囊菌门虫生真菌物种多样性}

从太保山森林公园采集的罹病昆虫及土壤样 品中分离虫生真菌, 通过形态特征初步判断, 然
后根据分子序列特征进行物种鉴定，共获得395株 菌株。

将5个基因矩阵序列进行拼接合并，得到4,620 个碱基对(bp)的序列，其中包括 $n r L S U 908 \mathrm{bp}$ 、 $n r S S U$ 1,026 bp 、EF-1 981 bp、RPB1 747 bp、RPB2 $958 \mathrm{bp}$ 。所有参与分析的多基因序列(共85条)(附录 1)在系统发育树(图1)中被分成了10个类群(clades 1-10), 外类群物种序列明显形成了 1 个独立的分支 (clade 10)。太保山森林公园子囊菌门虫生真菌分布 在8个类群(clades 1-4和clades 6-9)中, 每个类群归 为 1 个属，每个属中具有 $1-6$ 个物种，共包括 3 个科 (虫草科、线虫草科、麦角菌科) 9 个属 24 个物种, 即: 虫草属的Cordyceps tenuipes、C. cicadae、C. fumosorosea、C. cateniannulata、C. cateniobliqua、C. bifusispora，白僵菌属的Beauveria bassiana、B. pseudobassiana、B. medogensis、B. brongniartii、B. asiatica, 绿僵菌属的Metarhizium rileyi、M. lepidiotae、M. anisopliae, 线虫草属的Ophiocordyceps clavata、O. myrmicarum、O. myrmecophila, 多头霉属的Polycephalomyces ramosopulvinatus、 $P$. ramosus, 球束梗狍 属的Gibellula pulchra，刺束梗狍属的Akanthomyces sp., 蜡蚧菌属的Lecanicillium psalliotae, 紫狍菌属 的Purpureocillium lilacinum、P. atypicola (表1)。

太保山森林公园子囊菌门虫生真菌的优势种 属现象明显(表1，图2)。根据物种和菌株数量，优势 属为虫草属(clade 2) 6 个种199个菌株，占菌株总数 的 $50.4 \%$ ) 和白僵菌属(clade 3) (5个种 80 个菌株，占 菌株总数的 $20.2 \%)$ 。常见属包括刺束梗孢属(1个种 73 个菌株)、绿僵菌属( 3 个种 11 个菌株)和球束梗孢 属(1 个种 18 个菌株)。稀有属包括线虫草属(3个种 3 个菌株)、多头霉属( 2 个种 3 个菌株)、紫孢菌属 $(2$ 个 种 5 个菌株)、蜡蚧菌属( 2 个种 4 个菌株), 其检出菌株 数都大于 5 。

根据各物种的菌株数量和重要值, 优势种有 5 个: Akanthomyces sp. 、Beauveria bassiana、Cordyceps cicadae、C. fumosorosea、C. tenuipes, 其菌株数量 为52-73株，重要值在0.132-0.185之间。常见种有3 个: Beauveria pseudobassiana、Cordyceps cateniannulata、Gibellula pulchra, 其菌株数量为18-28株, 重要值在0.046-0.071之间。其他16个种：Beauveria asiatica 、B. brongniartii、B. medogensis、Cordyceps bifusispora 、C. cateniobliqua 、Lecanicillium psalliotae 、 
表1 太保山森林公园虫生真菌

Table 1 Entomogenous fungi in Taibaoshan Forest Park

\begin{tabular}{|c|c|c|c|c|}
\hline $\begin{array}{l}\text { 科 } \\
\text { Family }\end{array}$ & $\begin{array}{l}\text { 属 } \\
\text { Genus }\end{array}$ & $\begin{array}{l}\text { 物种 } \\
\text { Species }\end{array}$ & $\begin{array}{l}\text { 菌株数 } \\
\text { Strain number }\end{array}$ & $\begin{array}{l}\text { 重要值 } \\
\text { Importance value }\end{array}$ \\
\hline \multirow{14}{*}{$\begin{array}{l}\text { 虫草科 } \\
\text { Cordycipitaceae }\end{array}$} & 刺束梗狍属 Akanthomyces & Akanthomyces sp. & 73 & 0.185 \\
\hline & \multirow[t]{5}{*}{ 白僵菌属 Beauveria } & 球孢白僵菌 B. bassiana & 52 & 0.132 \\
\hline & & 假球孢白僵菌 B. pseudobassiana & 20 & 0.051 \\
\hline & & 墨脱白僵菌 B. medogensis & 4 & 0.010 \\
\hline & & 亚洲白僵菌 B. asiatica & 2 & 0.005 \\
\hline & & 布氏白僵菌 B. brongniartii & 2 & 0.005 \\
\hline & \multirow[t]{6}{*}{ 虫草属 Cordyceps } & 蝉花 C. cicadae & 56 & 0.142 \\
\hline & & 高雄山虫草 C. tenuipes & 56 & 0.142 \\
\hline & & 玫烟色虫草 C. fumosorosea & 54 & 0.137 \\
\hline & & 环链虫草 C. cateniannulata & 28 & 0.071 \\
\hline & & 斜链虫草 C. cateniobliqua & 4 & 0.010 \\
\hline & & 双梭狍虫草 C. bifusispora & 1 & 0.003 \\
\hline & 球束梗狍属 Gibellula & 丽球束梗狍 G. pulchra & 18 & 0.046 \\
\hline & 蜡蚧菌属 Lecanicillium & 刀孢蜡蚧菌 L.psalliotae & 3 & 0.008 \\
\hline \multirow{7}{*}{$\begin{array}{l}\text { 线虫草科 } \\
\text { Ophiocordycipitaceae }\end{array}$} & \multirow[t]{3}{*}{ 线虫草属 Ophiocordyceps } & 黄棒线虫草 O. clavata & 1 & 0.003 \\
\hline & & 红蚁线虫草 O. myrmicarum & 1 & 0.003 \\
\hline & & 蚁生线虫草 O. myrmecophila & 1 & 0.003 \\
\hline & \multirow[t]{2}{*}{ 多头霉属 Polycephalomyces } & 枝多头霉 P.ramosus & 2 & 0.005 \\
\hline & & 枝垫多头霉 P. ramosopulvinatus & 1 & 0.003 \\
\hline & \multirow[t]{2}{*}{ 紫狍菌属 Purpureocillium } & 淡紫紫孢菌 P. lilacinum & 4 & 0.010 \\
\hline & & 蜘蛛紫孢菌 P. atypicola & 1 & 0.003 \\
\hline \multirow{3}{*}{$\begin{array}{l}\text { 麦角菌科 } \\
\text { Clavicipitaceae }\end{array}$} & \multirow[t]{3}{*}{ 绿僵菌属 Metarhizium } & 金龟子绿僵菌 M. anisopliae & 6 & 0.015 \\
\hline & & 莱氏绿僵菌 M. rileyi & 3 & 0.013 \\
\hline & & 鳞腮绿僵菌 M. lepidiotae & 2 & 0.008 \\
\hline
\end{tabular}

Metarhizium anisopliae, M. lepidiotae, M. rileyi、 Ophiocordyceps clavata 、 O. myrmicarum 、O. myrmecophila、Purpureocillium atypicola、P. lilacinum、 Polycephalomyces ramosus和 $P$. ramosopulvinatus均 为太保山森林公园的稀有种, 其菌株数量为1-6株, 菌株总数所占百分比仅为 $9.6 \%$, 重要值在 $0.003-$ 0.015 之间。

\section{2 子囊菌门虫生真菌不同月份的消长动态}

太保山森林公园一年中不同月份不同物种虫 生真菌的数量变化较大(表2, 图3)。6-8月菌株检出 数量最多、物种丰富度和Shannon-Wiener多样性指 数最高。其中, 7 月的菌株检出率最高 (85株, 占总数 的 $21.4 \%$ ), 物种数较多(10种); 8 月检出的菌株数比7 月低(59株), 但物种丰富度 (15种)和多样性指数 (2.35)最高; 6 月检出的菌株数与 8 月相等(59株), 物 种丰富度(11种)和多样性指数(2.14)居中。9-11月检 出的菌株数(28-40株)和物种数量(7-8种)都下降,
多样性指数较低(1.69-1.80)。1-5月和12月检出的菌 株数量都很少( $\leq 20$ 株), 多样性指数较低(1.21-1.54)。

太保山森林公园子囊菌门虫生真菌1-4月和12 月的优势度指数较高(0.26-0.33), 1 月份最高(0.33); 5-11月的优势度指数偏低(0.11-0.23), 8 月最低 $(0.11)$ 。 $1 、 2 、 3$ 和 12 月的优势种都为 Cordyceps fumosorosea，4月的优势种为Beauveria bassiana。5 月和 10 月的优势物种为B. bassiana，6月的优势种为 Cordyceps tenuipes和C. cicadae, 7 月的优势物种为 $C$. cicadae, 8月的优势物种为Akanthomyces sp.、C. tenuipes和C. cateniannulata, 9月和11月的优势物种 都为Akanthomyces sp.。

优势种中，有 4 个物种分布的时间范围较宽， Akanthomyces sp. 在全年12个月中均能检出, $C$. tenuipes、C. fumosorosea和B. bassiana在全年11个月 中能检出, 虽然不同月份菌株数量有一定变化(大 多在 6-9月数量较多), 但波动相对较小。而 $C$. 


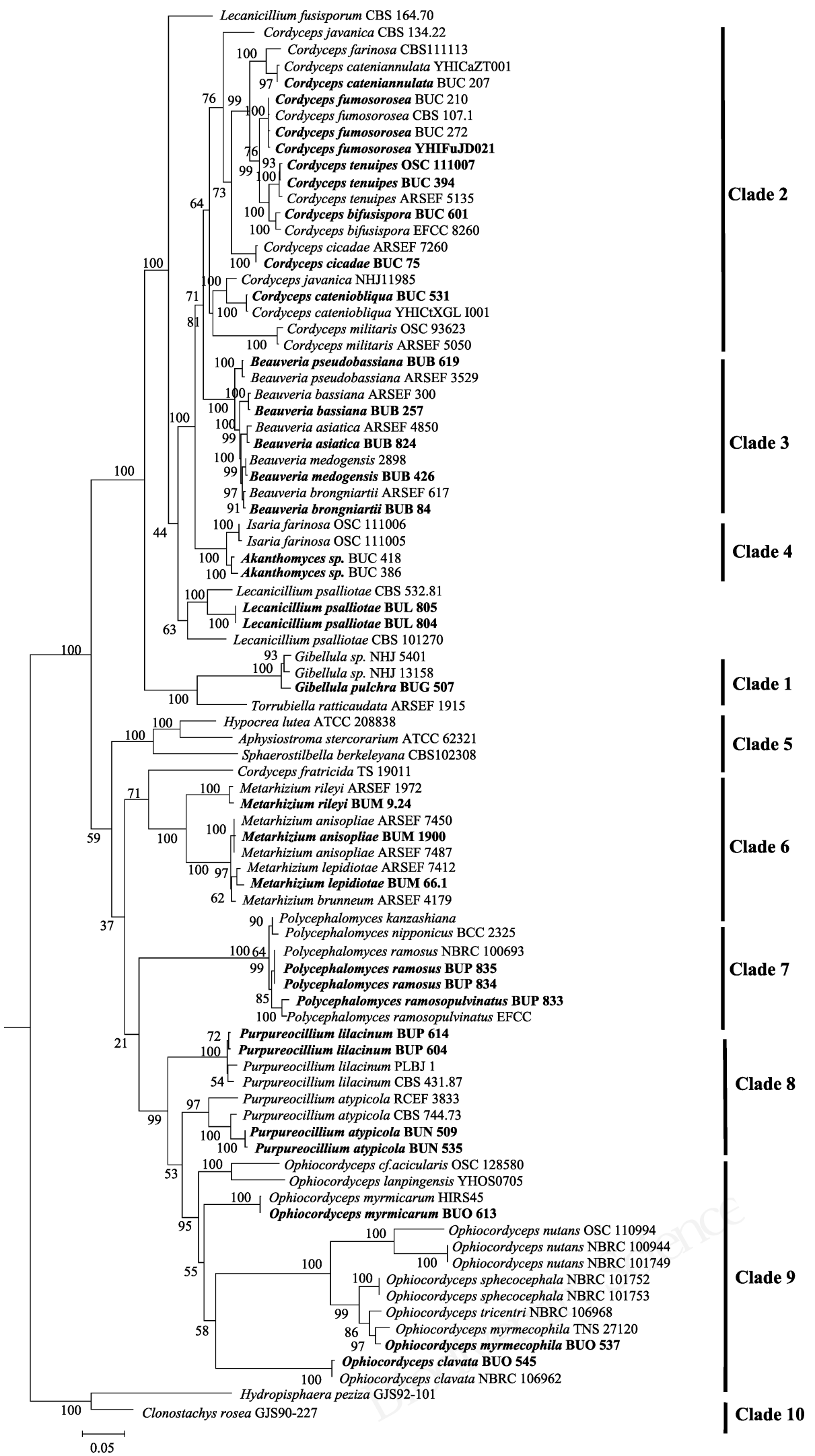

图1 太保山森林公园虫生真菌多基因( nrSSU, nrLSU, EF-1 $1 \alpha, R P B 1$ 和RPB2)系统发育树。加粗字体表示太保山虫生真菌的基 因序列。

Fig. 1 Phylogenetic tree of entomogenous fungi in Taibaoshan Forest Park based on multigene ( $n r S S U, n r L S U, E F-1 \alpha, R P B 1$ and $R P B 2$ ) dataset. The genetic sequences of entomogenous fungi in Taibaoshan Forest Park are shown in bold type. 


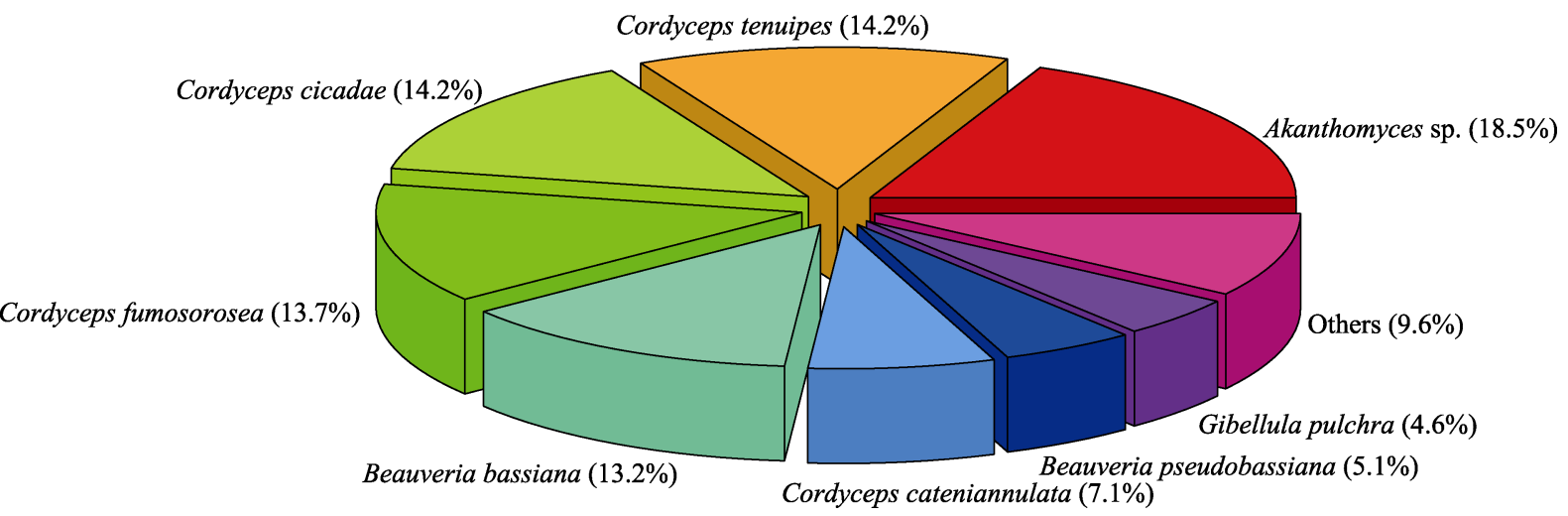

图2 太保山森林公园虫生真菌不同物种的菌株数量百分比

Fig. 2 Percentage of strain numbers of entomogenous fungal species in Taibaoshan Forest Park

表2 太保山森林公园虫生真菌不同月份的消长动态

Table 2 Monthly fluctuation of entomogenous fungi in Taibaoshan Forest Park

\begin{tabular}{llllllll}
\hline $\begin{array}{l}\text { 月份 } \\
\text { Month }\end{array}$ & $\begin{array}{l}\text { 菌株数 } \\
\text { No. of strains }\end{array}$ & $\begin{array}{l}\text { 物种丰富度 } \\
\text { Species richness }\end{array}$ & $\begin{array}{l}\text { 优势度指数 } \\
\text { Dominance index }\end{array}$ & $\begin{array}{l}\text { 均匀度 } \\
\text { Evenness }\end{array}$ & $\begin{array}{l}\text { Shannon-Wiener } \\
\text { index }\end{array}$ & $\begin{array}{l}\text { 空气温度 } \\
\text { Air temperature }\left({ }^{\circ} \mathrm{C}\right)\end{array}$ & $\begin{array}{l}\text { 空气湿度 } \\
\text { Air humidity }(\%)\end{array}$ \\
\hline 1 & 16 & 4 & 0.33 & 0.87 & 1.21 & $10 \pm 2.1$ & $44 \pm 3.2$ \\
2 & 20 & 6 & 0.26 & 0.86 & 1.54 & $14 \pm 2.8$ & $43 \pm 3.6$ \\
3 & 13 & 6 & 0.29 & 0.83 & 1.48 & $17 \pm 2.3$ & $40 \pm 3.1$ \\
4 & 11 & 5 & 0.26 & 0.91 & 1.47 & $21 \pm 2.2$ & $46 \pm 2.6$ \\
5 & 20 & 7 & 0.18 & 0.94 & 1.83 & $26 \pm 2.3$ & $68 \pm 4.3$ \\
6 & 59 & 11 & 0.14 & 0.89 & 2.14 & $28 \pm 1.1$ & $83 \pm 3.0$ \\
7 & 85 & 10 & 0.21 & 0.82 & 1.89 & $28 \pm 1.5$ & $75 \pm 5.9$ \\
8 & 59 & 15 & 0.11 & 0.87 & 2.35 & $29 \pm 0.8$ & $57 \pm 5.1$ \\
9 & 40 & 8 & 0.23 & 0.81 & 1.69 & $25 \pm 1.1$ & $63 \pm 4.0$ \\
10 & 28 & 8 & 0.20 & 0.87 & 1.80 & $24 \pm 1.2$ & $60 \pm 4.2$ \\
11 & 30 & 7 & 0.22 & 0.88 & 1.71 & $18 \pm 1.7$ & $51 \pm 1.5$ \\
12 & 14 & 6 & 0.29 & 0.82 & 1.48 & $14 \pm 1.6$ & $47 \pm 2.3$ \\
\hline
\end{tabular}

cicadae在不同月份数量波动较大, 只在5-9月能检 出, 6-7月检出的频率较高, 尤其在7月分布最丰富 (35株, 占该月菌株总数的 $41.2 \%$ ), 这也导致 7 月份 虫生真菌的菌株数量最多, 优势度高于 6 月和 8 月。

C. cateniannulata只在8月为优势物种, 集中分布于 6-8月，在3、9、10、12月也有1-2株菌株检出。

\section{3 讨论}

研究结果表明, 太保山森林公园中蕴藏着丰富 的虫生真菌资源, 其物种多样性较高、菌株数量丰 富, 一年12个月都有分布。保山市气候条件优越, 冬无严寒、夏无酷暑, 太保山森林公园里人类活动 频繁, 但主要集中于几条观光线路、山间石阶、已 开发的景点(玉佛寺、玉皇阁、武侯祠、动物园、山
顶游乐园等), 而茂密的植被覆盖区域很少有人涉 足, 加上公众的生态保护意识较强, 因此公园的核 心植被得到很好的保护，植被繁茂、生物物种趋于 稳定, 生态结构复杂、昆虫种类繁多, 有利于虫生 真菌维持多样性。微生物群落中的物种多样性越高, 群落越稳定(Yosiaki, 1997), 其功能发挥明显高于简 单群落(Maherali \& Klironomos, 2007; Van Elass et al, 2012)。太保山森林公园子囊菌门虫生真菌的物种多 样性较高, 表明其群落较稳定。

太保山森林公园的虫生真菌优势种属现象非 常明显。从分离到的菌株数量看, 优势属为虫草属 和白僵菌属, 其检出菌株数占总数的 $70.6 \%$, 这 2 个 属都为世界广布属，广泛分布于热带、亚热带和温 带地区。菌株数超过50株的优势种有5种, 其检出菌 


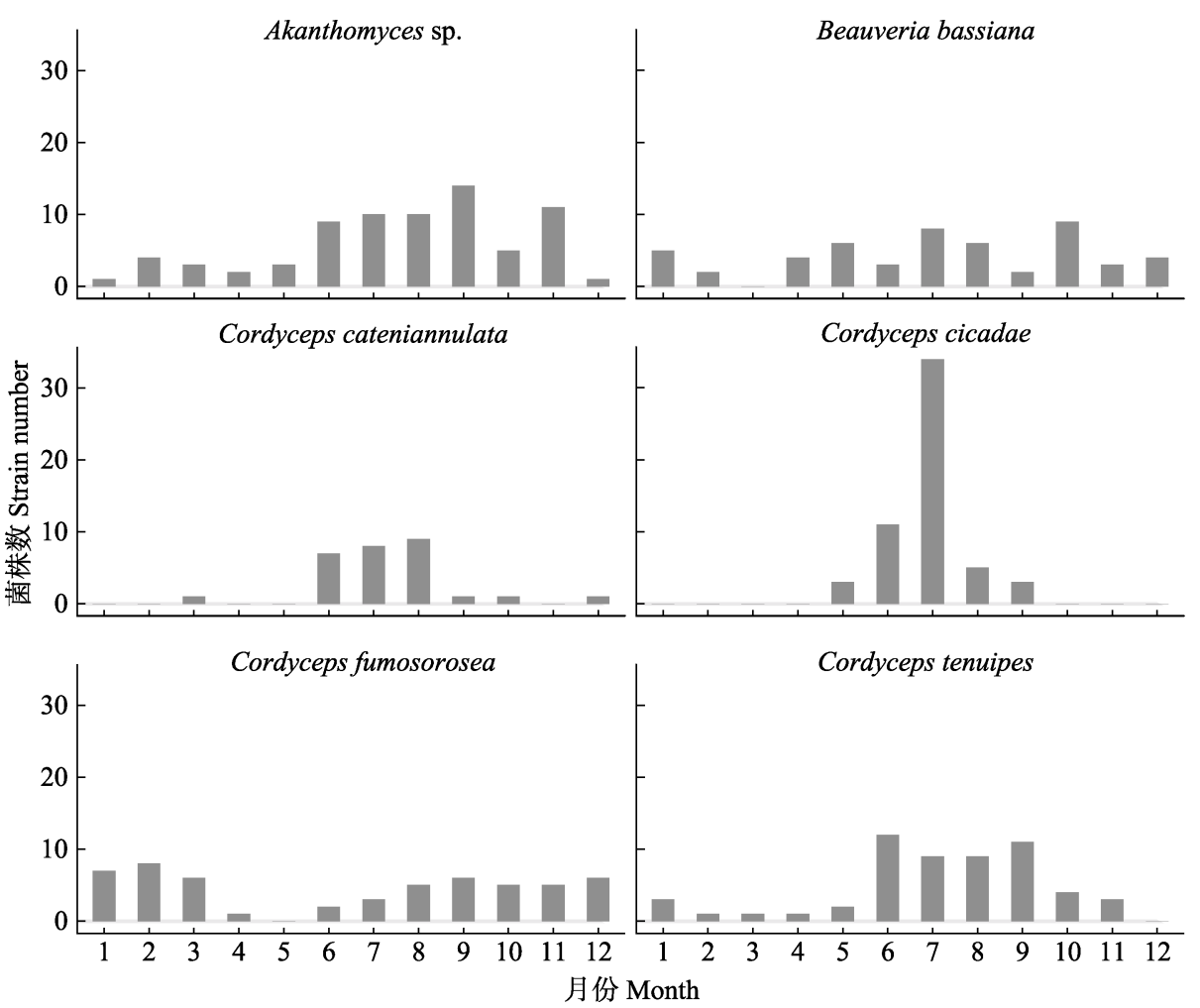

图3 太保山森林公园虫生真菌优势物种的消长动态

Fig. 3 Monthly dynamics for dominant species of entomogenous fungi in Taibaoshan Forest Park

株数占总数的 $73.7 \%$ 。结果表明, 在太保山森林生态 系统中虫生真菌的优势种属占主要地位, 对森林害 虫的调控起着重要的作用。

不少研究都表明, 虫生真菌的种群数量具有明 显的季节变化规律(王四宝等, 2004; 刘玉军等, 2018)。太保山森林公园子囊菌门虫生真菌全年都有 分布, 但不同月份虫生真菌物种多样性和真菌数量 变化较大。6-8月(夏季)为高温高湿月份(温度28$29^{\circ} \mathrm{C} 、$ 湿妄 $\left.57 \%-83 \%\right)$, 气候条件适宜多数虫生真菌 的生长繁殖, 虫生真菌数量最多、物种多样性最高; 1-5月和12月温湿度都降低, 虫生真菌的数量最少、 物种多样性最低。王四宝等(2004)认为大别山虫生 真菌的丰度和多度在夏季都达到了最高峰。李文英 等(2003)在山西省的研究也表明, 温湿度越高, 主 要植被区的虫生真菌的物种越多样化。而陈名君等 (2007)的研究表明, 温湿度较低的月份, 琅躯山虫 生真菌多样性指数和均匀度较大, 而6-8月的多样 性指数和均匀度较低。

在优势种中, Akanthomyces sp.、Cordyceps tenuipes、C. fumosorosea和Beauveria bassiana在一年大 部分时间都能检测到, 尤其是最优势物种Akan- thomyces sp.在一年12个月中都检测到, 说明这4种 虫生真菌对季节变化适应能力较强, 有利于对森林 害虫的持续控制。其中, C. fumosorosea在温湿度最 低的月份(1-3月、12月)是最优势物种, 主要从土壤 中通过昆虫诱导分离得到, 真菌以分生孢子形态宿 存于土壤中, 对不良环境的耐受能力较强。C . cicadae的分布较集中于 $6 、 7$ 月, 尤其是7月数量最多, 说明该物种受季节变化影响较大。太保山森林公园 2016年7月蝉花的数量尤其多，同时6、7月降雨量大, 雨天持续时间长, 高温 $\left(28^{\circ} \mathrm{C}\right)$ 、高显 $(75 \%-83 \%)$ 的环 境是蝉花大量发生的关键因子。但蝉花的数量分大 小年, 不同年份可能有波动, 这需要进一步研究。 可以看出, 太保山森林公园优势种有的因环境适应 能力强、分布时间长而处于优势地位, 而有的是因 为集中在短期内大量生长繁殖而处于优势地位。

本研究由于取样范围及采集到的被感染昆虫 数量有限, 调查到的虫生真菌主要归属于子囊菌门, 其中麦角菌科中侵染蚧壳虫的虫生真菌, 如 Hypocrella、Moelleriella、Samuelsia 、Regiocrella 和 Aschersonia等都未能采集到, 在后续研究中尚需对 此类群的虫生真菌加强关注。 


\section{参考文献}

Chen MJ, Huang B, Wang M, Wu SZ, Fan MZ, Zou YD, Li ZZ (2007) Species diversity and seasonal change of entomogenous fungi in Langya Mountains Nature Reserve. Chinese Journal of Applied Ecology, 18, 2075-2079. (in Chinese with English abstract) [陈名君, 黄勃, 王蒙, 吴仕振, 焚美 珍, 邹运鼎, 李增智 (2007) 琅㑚山虫生真菌物种多样性 和季节变化. 应用生态学报, 18, 2075-2079.]

Chen ZH, Dai YD, Yu H, Yang K, Yang ZL, Yuan F, Zeng WB (2013) Systematic analyses of Ophiocordyceps lanpingensis sp. nov., a new species of Ophiocordyceps in China. Microbiological Research, 168, 525-532.

Chen ZH, Yang XN, Sun NJ, Xu L, Zheng Y, Yang YM (2018) Species diversity and vertical distribution characteristics of Metarhizium in Gaoligong Mountains, southwestern China. Biodiversity Science, 26, 1308-1317. (in Chinese with English abstract) [陈自宏, 杨晓娜, 孙宁静, 徐玲, 郑元, 杨宇明 (2018) 中国西南高黎贡山绿僵菌物种多样性及 其垂直分布特征. 生物多样性, 26, 1308-1317.]

Dai YD, Yu H, Zeng WB, Yang JY, He L (2016) Multilocus phylogenetic analyses of the genus Isaria (Ascomycota, Cordycipitaceae). Mycosystema, 35, 147-160. (in Chinese with English abstract) [代永东, 虞泓, 曾文波, 杨俊媛, 何 璐 (2016) 多基因联合分析棒束孢属Isaria (Ascomycota, Cordycipitaceae)系统发育关系. 菌物学报, 35, 147-160.]

Jiang X, Wang CY, Li LZ, Wang X, Teng LR, Zhou YL (2017) Activity comparison study on Paecilomyces hepiali, Cordyceps militaris and wild Cordyceps sinensis. Journal of Changchun University of Traditional Chinese Medicine, 33, 544-547. (in Chinese with English abstract) [姜雪, 王春月, 李兰洲, 王雪, 滕利荣, 周毓麟(2017) 蝙蝠蛾拟青霉及 蛹虫草与野生冬虫夏草活性比较. 长春中医药大学学报, 33, 544-547.]

Kepler RM, Humber RA, Bischoff JF, Rehner SA (2014) Clarification of generic and species boundaries for Metarhizium and related fungi through multigene phylogenetics. Mycologia, 106, 811-829.

Kepler RM, Luangsa-ard JJ, Hywel-Jones NL, Quandt CA, Sung GH, Rehner SA, Aime MC, Henkel TW, Sanjuan T, Zare R, Chen MJ, Li ZZ, Rossman AY, Spatafora JW, Shrestha B (2017) A phylogenetically-based nomenclature for Cordycipitaceae (Hypocreales). IMA Fungus, 8, 335-353.

Keyser CA, Licht HHDF, Steinwender BM, Meyling NV (2015) Diversity within the entomopathogenic fungal species Metarhizium flavoviride associated with agricultural crops in Denmark. BMC Microbiology, 15, 249.

Li WY, He YC, Wang JM, Zhang ZG, Zhang XH (2003) Ecological diversity of entomogenous fungi in Shanxi Province. Biodiversity Science, 11, 53-58. (in Chinese with English abstract) [李文英, 贺运春, 王建明, 张作刚, 张仙
红 (2003) 山西省虫生真菌生态多样性研究. 生物多样 性, 11, 53-58.]

Li ZZ (2015) History, progress and current status of the application of fungi against pest insects in China. Chinese Journal of Biological Control, 31, 699-711. (in Chinese with English abstract) [李增智 (2015) 我国利用真菌防治害虫 的历史、进展及现状. 中国生物防治, 31, 699-711.]

Liu YJ, Zhou HB, Dong XR, Xu SW, Cai QX (2018) Species diversity and distribution characteristics of entomogenous fungi in Zipeng Mountain National Forest Park. Chinese Journal of Biological Control, 34, 568-573. (in Chinese with English abstract) [刘玉军, 周海波, 董先茹, 许舒雯, 蔡群 兴 (2018) 紫蓬山国家森林公园虫生真菌物种多样性与 分布特点. 中国生物防治学报, 34, 568-573.]

Luangsa-ard JJ, Mongkolsamrit S, Thanakitpipattana D, Khonsanit A, Tasanathai K, Noisripoom W, Humber RA (2017) Clavicipitaceous entomopathogens: New species in Metarhizium and a new genus Nigelia. Mycological Progress, 16, 369-391.

Maherali H, Klironomos JN (2007) Influence of phylogeny on fungal community assembly and ecosystem functioning. Science, 316, 1746-1748.

Quandt CA, Kepler RM, Gams W, Araújo JPM, Ban S, Evans HC, Hughes D, Humber R, Hywel-Jones N, Li ZZ, Luangsa-ard JJ, Rehner SA, Sanjuan T, Sato H, Shrestha B, Sung GH, Yao YJ, Zare R, Spatafora JW (2014) Phylogenetic-based nomenclatural proposals for Ophiocordycipitaceae (Hypocreales) with new combinations in Tolypocladium. IMA Fungus, 5, 121-134.

Sinha KK, Choudhary AK, Kumari P (2016) Entomopathogenic fungi. In: Ecofriendly Pest Management for Food Security (ed. Omkar O), pp. 475-505. Academic Press, Pittsburgh.

Sung GH, Hywel-Jones NL, Sung JM, Luangsa-ard JJ, Shrestha B, Spatafora JW (2007) Phylogenetic classification of Cordyceps and the clavicipitaceous fungi. Studies in Mycology, 57, 5-59.

Van Elass JD, Chiruazzi M, Mallon CA, Elhottová D, Krištůfek V, Salles JF (2012) Microbial diversity determines the invasion of soil by a bacteria pathogen. Proceedings of the National Academy of Sciences, USA, 109, 1159-1164.

Wang M, Yin YP, Wang ZK, Liu JJ, Liao YF (2014) Multilocus phylogenetic analysis of the taxonomic status of 10 strains of Metarhizium. Plant Protection, 40(5), 14-21. (in Chinese) (in Chinese with English abstract) [王萌，殷幼平， 王中康, 刘娟娟, 廖玉凤 (2014) 10 株绿僵菌菌株分类地 位的多基因系统进化分析. 植物保护, 40(5), 14-21.]

Wang SB, Liu JN, Huang B, Fan MZ, Li ZZ (2004) The community structure and ecological distribution of entomogenous fungi in Dabie Mountains. Mycosystema, 23, 195-203. (in Chinese with English abstract) [王四宝, 刘竞男, 黄勃, 樊 美珍, 李增智 (2004) 大别山地区虫生真菌群落结构与 
生态分布. 菌物学报, 23, 195-203.]

Xue Y, Chen LP (2006) Statistical Modeling and R Software.

Tsinghua University Press, Beijing. (in Chinese) [薛毅, 陈立

萍 (2006) 统计建模与 R 软件. 清华大学出版社, 北京.]

Yosiaki Itô (1997) Diversity of forest tree species in Yanbaru, the northern part of Okinawa Island. Plant Ecology, 133, 125-133.

(责任编委：刘杏忠 责任编辑：时意专)

\section{附录 Supplementary Material}

附录1 本文用于系统发育分析的虫生真菌物种多基因序列信息

Appendix 1 Species and voucher information of entomogenous fungi of ascomycota for the multigene phylogenetic analysis in this paper

http://www.biodiversity-science.net/fileup/PDF/2019135-1.pdf 